\title{
Fabrication and Performance of a Microbial Fuel Cell: Utilization of Modified Nafion Membrane with Carbon Powder as Separator and Bio-Anode
}

\author{
Mustapha Abdeldjabar Charef ${ }^{1,2^{*}}$, Hakima Kebaili ${ }^{1}$, Mostefa Kameche ${ }^{1}$, and Christophe Innocent ${ }^{3}$ \\ ${ }^{1}$ Laboratoryof Physico-Chemistry of Materials, Catalysis, and Environment, University of Sciences and Technology of Oran- \\ Mohammed-Boudiaf, M'Nouar, BP 1505, Oran, Algeria \\ ${ }^{2}$ University HassibaBenbouali of Chlef, B.P. 78C, Ouled Fares Chlef 02180, Algeria \\ ${ }^{3}$ European Institute of Membranes, University of Montpellier, CC 047, Place Eugene Battalion, 34095 Montpellier Cedex 5, France
}

*Corresponding author:

email: charefmustapha31000@hotmail.com

Received: December 20, 2019

Accepted: September 21, 2020

DOI: $10.22146 / \mathrm{ijc} .52728$

\begin{abstract}
A Microbial Fuel Cell (MFC) was conceived by using garden soil as a source to culture. It was then utilized as a bio-catalyst to decompose waste organic matter, reduce pollution from the soil, and produce energies. The MFC was composed of a bio-anode inoculated with a mixture of garden compost leachate and an abiotic stainless steel cathode. Besides, the bio-anode consisted of a Nafion membrane modified with carbon. The microorganisms agglomerated under polarization and formed electroactive bio-film onto bio-anode. In the preliminary test of MFC, potassium hexacyanoferrate has been utilized as catholyte, to enhance the reduction of proton and electrons resulting in a higher voltage. However, this electrolyte is toxic and oxidized rapidly, thus substituted by the hydrochloric acid. The results showed that the MFC with modified Nafion, gave relatively high current-density $379 \mathrm{~mA} / \mathrm{m}^{2}$ in two days, whereas the conventional biofuel cell without modification attained the current-density $292 \mathrm{~mA} / \mathrm{m}^{2}$ in four days. Nevertheless, both cells yielded almost the same current density of $20 \mathrm{~mA} / \mathrm{m}^{2}$ during 60 days. Although it has been used for a long time, the modified Nafion has not been corroded and preserved its physicochemical properties.
\end{abstract}

Keywords: microbial fuel cell; garden soil leachate; Nafion117 membrane; carbon powder; surface modification; bioenergy; electrochemical characterization

\section{- INTRODUCTION}

Microbial fuel cells (MFCs) are devices that can generate electricity from biomass using bacteria as the catalyst [1-5]. Future applications of MFCs include wastewater treatment and bioelectricity generation for example biosensors [6]. Research on MFCs was started by using low-molecular-weight molecules such as glucose and acetate as fuels [7-8]. Complex substrates such as cellulose and chitin were then tested to extend MFC applicability [9]. Wastes and wastewaters of different origins: food wastewaters [10], meat [11] dairy [12] industries, farm wastes such as farm manure [12], and corn stover [13] have been also investigated for MFC application. When MFC's were tested, the higher performance was obtained for the more complex substrates: acetate generated $506 \mathrm{~mW} / \mathrm{m}^{2}$ [7], while hydrolyzed corn stover generated $971 \mathrm{~mW} / \mathrm{m}^{2}$ [14].

In the anode compartment of the MFC, microorganisms oxidize the substrates (such as glucose [15] and acetate [16]) to generate electrons and protons. The electrons are transported to the anode and they travel through a resistor to the cathode. Protons migrate to the cathode compartment through a proton-exchange membrane. At the cathode (the electron acceptor), the oxygen is reduced to yield water droplets. By this process, the biodegradable organics are removed in the anode chamber, and current is generated as electrons flow from the anode to the cathode [17]. 
The purpose of this study is to modify the cationexchange membrane (Nafion117) with carbon graphite powder to avoid corrosion of the bio-anode for a long-time usage ( 3 months). The modified membrane was also used as a separator between the two compartments of MFC, to stimulate the proton conduction and the oxidation of the fuel at its surface. In addition, the physicochemical properties of the used membrane were also determined to see if the membrane has preserved its characteristics. We determined the transport number of the counter-ions and the limiting current density respectively by using Hittorf and volt-amperometry methods.

\section{- EXPERIMENTAL SECTION}

\section{Materials}

The materials used to elaborate the MFC were garden compost (Neuhaus-France), potassium chloride (KCl, Aldrich or Fluka), Sodium acetate (CARLO ERBA), osmosis demineralized water; potassium hexacyanoferrate(III) (Sigma-Aldrich), carbon felt (Alfa Aesar, $6.35 \mathrm{~mm}$ thick, anode), carbon powder (TIMREX KS 6 GRAPHITE), Nafion117 membrane (DuPont de Nemours-USA), and Stainless steel 316 (cathode).

\section{Procedure}

\section{Preparation of garden compost}

The microbial flora was extracted by lixiviation, from the mixture of $500 \mathrm{~g}$ of garden soil (Neuhaus) and $1 \mathrm{~L}$ of a $\mathrm{KCl}$ solution. The mixture was placed in an Erlenmeyer flask and stirred for $72 \mathrm{~h}$. Then the mixture was filtered using a paper filter to give the garden compost that having an ionic conductivity of $4.5 \mathrm{mS} / \mathrm{cm}$ and $\mathrm{pH} 5$.

\section{Electrochemical characterization}

The device used in the electrochemical experiments (i.e. cyclic voltammetry and impedance spectroscopy) consisted of a cell with three electrodes: working electrode (carbon felt), reference electrode $\left(\mathrm{Ag} / \mathrm{AgCl}_{2}\right)$, and counter-electrode $(\mathrm{Pt})$. The electrochemical analysis was carried out under experimental conditions controlled by the potentiostat-galvanostat Voltalab-40 functioning with the Volta-Master operating software. The potentiostat allows the potential of the working electrode to be checked against the potential of the reference electrode and the passage of electric current between the working electrode and the counter electrode.

Anodes were made of carbon felt. Meanwhile, the counter-electrode was made of platinum because of its resistance to corrosion in the electrolytic solution. Working and counter-electrodes were connected to the electrical circuit by copper wires. Silver chloride electrode was used as a reference and the potentials were monitored with a multi-channel provided in the potentiostat-galvanostat apparatus. The electrochemical cell was filled with $80 \mathrm{~mL}$ of $\mathrm{KCl}(60 \mathrm{mM})$. When the current started, an acetate was added to recover the $20 \mathrm{mM}$ initial concentration to prevent any substrate limitation.

Cyclic voltammetry curves $(\mathrm{CV})$ were recorded at $10 \mathrm{mVs}^{-1}$. Polarization was interrupted after a polarization depending on the experimental run, and the anode potential was relaxed. It took about $10 \mathrm{~min}$ for the anodes to reach a stable open circuit potential (OCP) and perform successive cycles. The potential of the working electrode was scanned from the value used during polarization to the upper limit of $1 \mathrm{~V}$ down to$0.1 \mathrm{~V}$ and finally back to the starting value. The third and the fourth cycle curves were generally perfectly superimposed thus only the fourth cycle was reported here. Current densities were expressed concerning the projected surface area.

In this work, EIS was used to study the evolution of biofilm formed from garden compost leachate on anodes polarized at a constant potential $(+0.1 \mathrm{~V} / \mathrm{ESH})$ during a certain time. Characterization of the working electrode used, a piece of carbon felt is first recorded. A biofilm was then grown on carbon felt anode system and characterized. The EIS measurement was automatically performed giving an open circuit voltage (OCV) of +0.1 V/ESH. The parameters adjusted into the Volta-Master software were amplitude of $10 \mathrm{mV}$ (i.e. $10 \% \mathrm{OCV}$ ) and a frequency range from $100 \mathrm{kHz}$ to $100 \mathrm{MHz}$. The Nyquist impedance spectra were analyzed by fitting experimental data with theoretical data using the $\mathrm{Z}$ fit tool provided in the software. Randomization was added before the fitting to select the most suitable set of parameter values. 
Surface analysis using scanning electron microscopy. To visualize the formation of the electroactive biofilm onto the surface of carbon felt bioanode, scanning electron microscopy was performed. In effect, a small sample of the biofilm was sliced from the surface of the electrode and transferred to a glass substrate to analyze. Therefore, before and at the end of polarization at $0.1 \mathrm{~V} / \mathrm{ESH}$, the bio-anode was extracted from the reactor and imaged by scanning microscopy. In some electroactive biofilms, the association of Gramnegative and Gram-positive bacteria has led to better electroactivity than the strains alone [18].

\section{Preparation of modified membrane}

The modified membrane was used both as a bioanode and a separator between the anode and cathode compartments in MFC. The mixture was prepared from carbon powder and deionized water. This mixture was placed in an Erlenmeyer flask and stirred with a magnetic stirrer for $24 \mathrm{~h}$. The Nafion117 was immersed in the carbon solution under stirring for $24 \mathrm{~h}$ and then dried in an oven for $5 \mathrm{~min}$ at $30^{\circ} \mathrm{C}$. It was immersed again in carbon solution under stirring for $24 \mathrm{~h}$ and dried. The chemical modification of the membrane enables the formation of a thin layer containing carbon graphite. Fig.
1 and 2 show the images of pristine and modified membranes.

\section{MFC construction}

Following our previous experiments on the conception of bio-electrochemical devices, we have carried on other experiments with newly designed MFCs [4]. These latter consist of two parallel $100 \mathrm{~mL}$ sized chambers, separated with the Nafion membrane. The types of MCFs are grouped in Table 1. The bio-anode was immersed into the leachate of the compost garden mixed with $20 \mathrm{mM}$ sodium acetate (used as fuel) and $\mathrm{KCl}(60 \mathrm{mM})$ as support conducting electrolyte. The cathode was dipped into the hydrochloride acid solution of potassium hexacyanoferrate(III) at open-air, where oxygen and electrons produced by oxidation are combined into a proton to yield water droplets. The MFC electrical circuit was closed with an external resistance of $1000 \Omega$ to allow the electron transfer from anode to cathode, while protons were exchanged through the Nafion membrane inside the cell. The voltmeter (GEF G 49) was plugged in parallel to follow the evolution of the voltage during the time. The $\mathrm{pH}$ meter (Hanna) and conductometer (Hanna) were utilized to control the transfer of ionic species from one compartment to another.

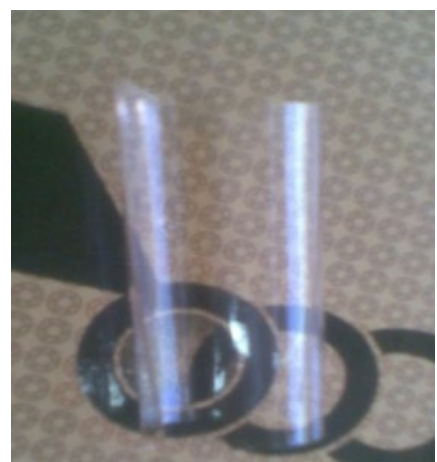

Fig 1. Image of Nafion117

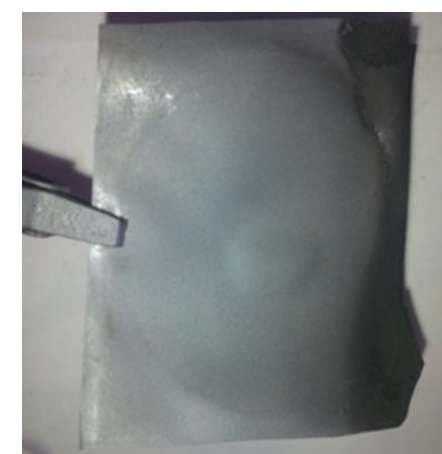

Fig 2. Image of modified Nafion 117

Table 1. Limiting current densities of Nafion117 in aqueous solutions (0.1 M)

\begin{tabular}{lccc}
\hline Limiting Current Density $\left(\mathrm{mA} / \mathrm{cm}^{2}\right)$ & $\mathrm{H}^{+}$ & $\mathrm{K}^{+}$ & $\mathrm{Na}^{+}$ \\
\hline Nafion117 & 32.59 & 7.33 & 5.83 \\
Nafion117 modified with carbon powder & 20.02 & 4.83 & 3.96 \\
Nafion117 used 10 months & 26.23 & 6.01 & 4.92 \\
\hline
\end{tabular}




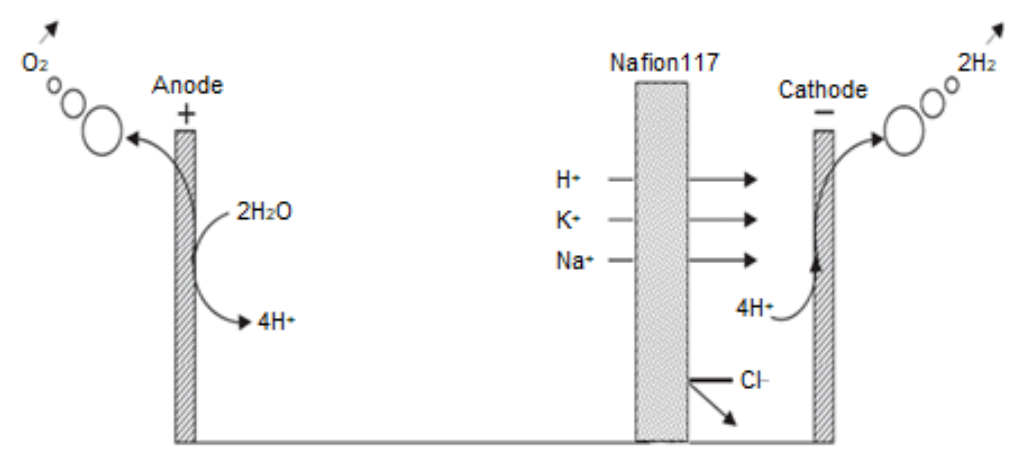

Fig 3. Determination of transport number of counter ions through a cation exchange membrane using the Hittorf method

\section{MFC characteristics}

Polarization curves for the MFCs were obtained by changing the external resistance in the range (100-10000 $\Omega)$. Values of the external resistance (R) and corresponding voltages $(\mathrm{V})$ were measured by a digital multimeter. The current density $(\mathrm{J})$ was calculated as $\mathrm{J}=$ $\mathrm{V} /(\mathrm{RA})$, and the power density as $\mathrm{P}=\mathrm{iV} / \mathrm{A}$, where $\mathrm{A}$ is the projected surface area of the anode. The internal resistance of the MFC was obtained as the gradient of the polarization curve over the range excluding concentration and activation polarization. The maximum power output was determined from the power curve.

\section{Membrane characterization}

Transport number of counter-ion. The permselectivity of a cation exchange membrane is characterized by measurements of the transport number of the counter-ion. This latter may be defined as the fraction of the current transported by the counter-ion, through the membrane when an electric field is applied. In a perfect selective membrane, the transport number of the counter-ion is equal to unity, while that of the co-ion is supposed to be zero. Theoretically, the sum of transport numbers is equal to 1 . The transport number of a counterion crossing a cation exchange membrane may be given by Faraday's $2^{\text {nd }}$ law [19]:

$\mathrm{t}_{\mathrm{A}+}=\frac{\mathrm{Z}_{\mathrm{A}+} \mathrm{n}_{\mathrm{A}+} \mathrm{F}}{\text { It }}$

where $\mathrm{Z}_{\mathrm{A}+}$ is the valence of counter-ion, $\mathrm{n}_{\mathrm{A}+}$ is the number of moles crossing the membrane, F refers to Faraday's constant, I represents the electrical current applied, and $t$ is the time of electrodialysis. The measurements of ion transport numbers were carried out using Hittorf's method as shown in Fig. 3.

Current-voltage measurements. Current-voltage curves were obtained using the cell represented by Fig. 4. It is made of Plexiglas and consists of two symmetrical compartments $(\mathrm{V}=75 \mathrm{~mL})$. The feed electrodes consist of titanium sheets coated with platinum. The effective area of the membrane was $5 \mathrm{~cm}^{2}$. In addition to the feed platinized-titanium electrodes, two silver-silver chloride electrodes were placed nearby the membrane sides, for measurement of the transmembrane potential difference for each value of the applied current. To control both the current intensity and the voltage, two digital multimeters were placed in series and parallel respectively.

Limiting current density. The influence of each electrolytic salt concentration on the current-voltage curve

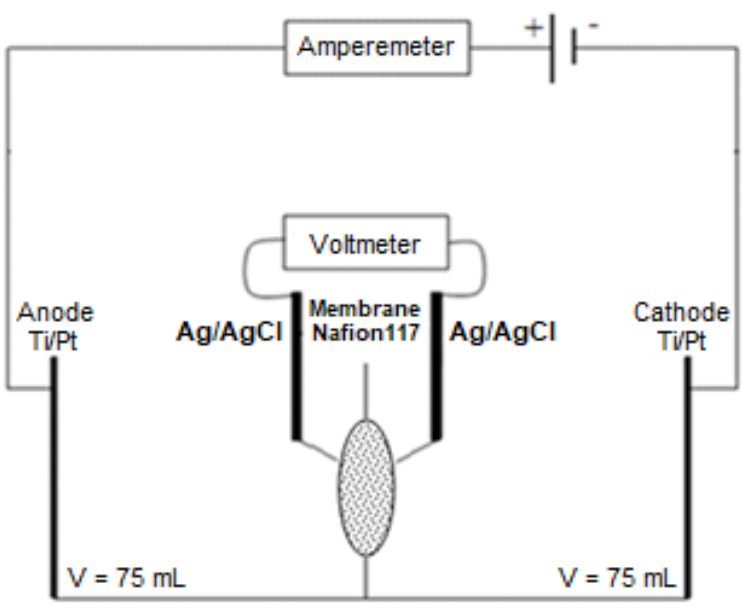

Fig 4. Schematic diagram of a two-compartment electrolytic cell used for current-voltage measurements 
was studied and the results are shown in Fig. 6 and 7, respectively. It is also observed that the value of the limiting current density increases with increasing bulk solution concentration. The limiting current density $\mathrm{i}_{\text {lim }}$ can be calculated according to the following formula $[16,31]$.

$$
\mathrm{i}_{\lim }=\frac{\mathrm{FDC}^{\mathrm{b}}}{\Delta \mathrm{t}^{+} \delta}
$$

where $\mathrm{F}$ is the Faraday constant, $\mathrm{C}^{\mathrm{b}}$ is the concentration of the bulk solution, Dis the salt diffusion coefficient, $\delta$ is the diffusion boundary layer thickness, and $\Delta \mathrm{t}^{+}$is the being the difference between the transport number in membrane and solution. Eq. (2) assumes that a concentration gradient exists only in the direction perpendicular to the membrane surface, that is, the flow assuming that $\mathrm{D}, \delta$, and $\Delta \mathrm{t}^{+}$remain constant. Eq. (2) predicts a proportional relationship between the limiting current density and the bulk solution concentration.

\section{- RESULTS AND DISCUSSION}

\section{Current-Voltage Curves}

The current-voltage (I-V) curves of the Nafion117 membrane are presented in Fig. 6 and 7 for various aqueous electrolytic solutions. These figures show a typical example of a measured current-voltage curve. Three regions can be distinguished. The first region is a linear relationship obtained between the applied current and the voltage drop (generally referred to as the Ohmic region). As the current density increases, the

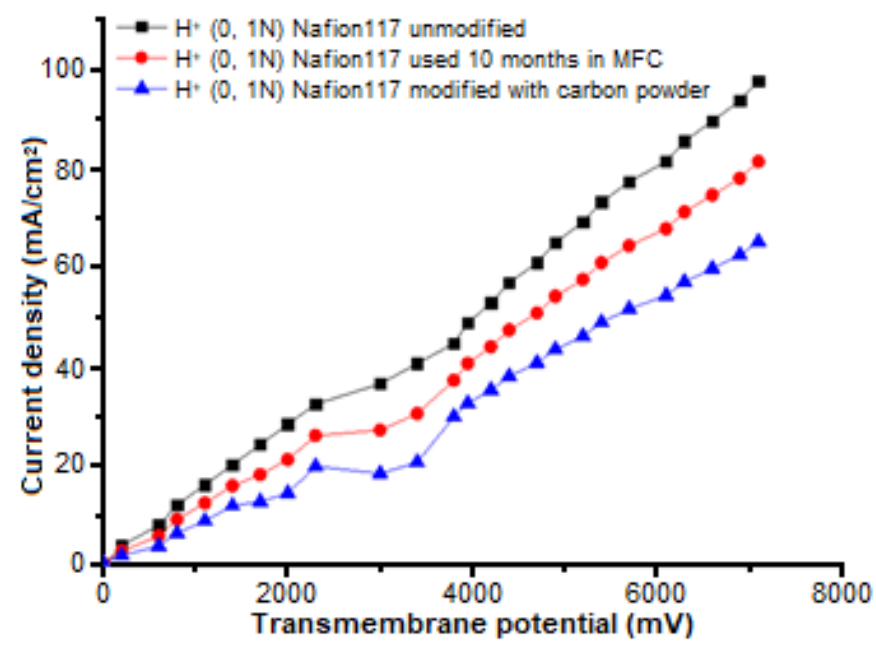

Fig 6. I-V curves of the different membranes conditioned with $\mathrm{H}^{+}$ concentration polarization becomes more pronounced. The concentration in the dilute boundary layer decreases rapidly and the resistance rises. As a result, a deviation of the linear behavior occurs and a limiting current density is reached (represented by a current plateau). Beyond this point, the current density increases again, yielding an over limiting density (due to water dissociation). The figures show that the first two regions are smooth, while the over limiting region is characterized by a considerable scatter, resulting from hydrodynamic instabilities in this region.

The values of related electrical parameters are extracted from these curves and are given in Table 1. They

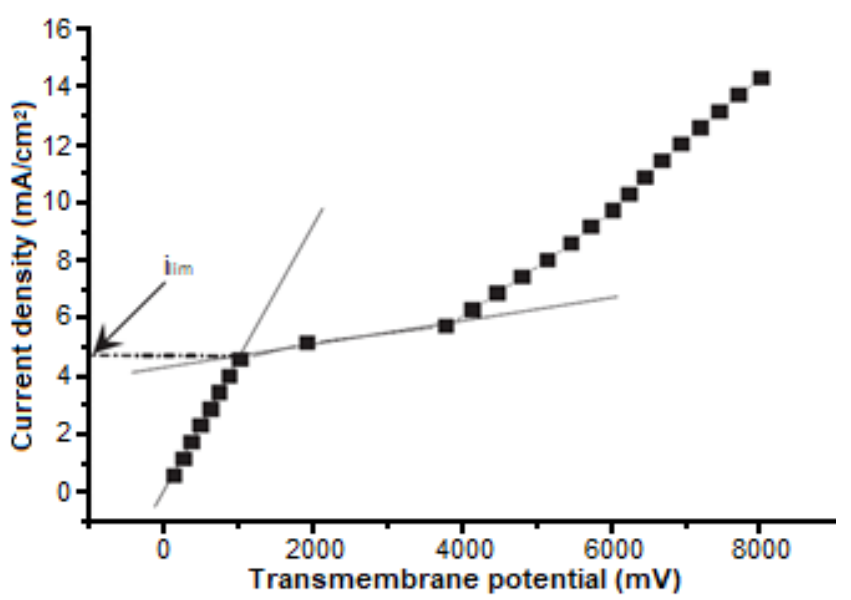

Fig 5. Determination of the limiting current density of Nafion117 membrane using Cross-Section of Tangents method

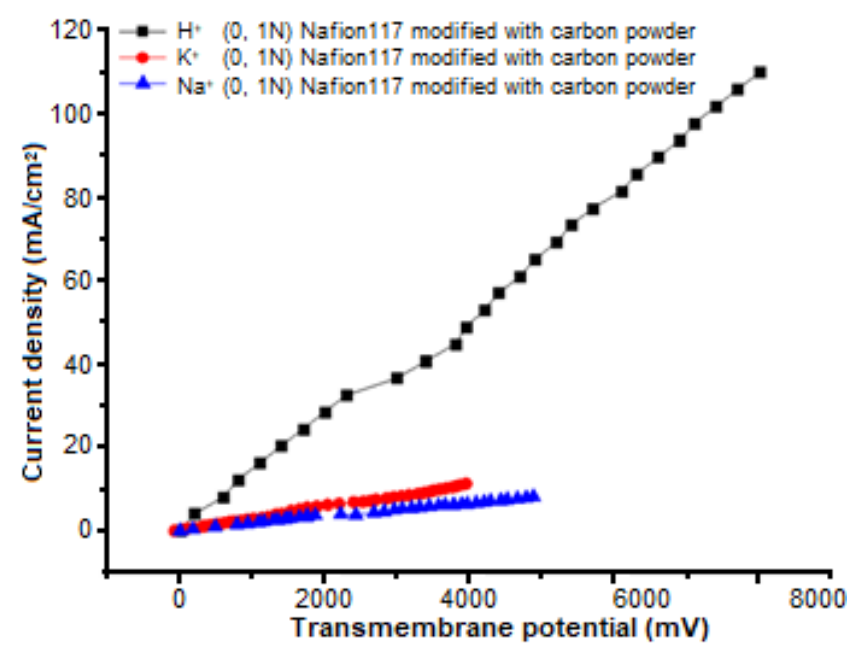

Fig 7. I-V curves of the different membrane conditioned with $\mathrm{H}^{+}, \mathrm{Na}^{+}$, and $\mathrm{K}^{+}$separately 
are following the concentration polarization and electroconvection phenomena, as mentioned earlier. They are similar to those previously reported in the literature [20] and seem to reflect differences of counterion diffusion coefficients through the membrane and also the ionic conductivity of the solution.

The limiting current density can be determined from the relationship between the current and corresponding potential [21-22]. It is obtained by measuring the transmembrane potential as a function of the applied current. Three graphical methods can be used to determine this limiting current density. We used the method of Cross-Section of Tangents (CST). The limiting current is determined in the relationship between the potential and the current in the characteristic (I-V), where the slope (the reciprocal of the resistance) is changed, following water dissociation on the surface of the ion exchange membrane [23-25]. As shown in Fig. 5, the limiting current density can be determined by drawing the two slopes of the Ohmic region and plateau that intersect at the limiting current. Table 1 shows limiting current densities for 3 membranes in several aqueous electrolytes.

The characterization results show that the modification of the Nafion 117 membrane with carbon powder causes an increase in its transport performance, especially in the case of $\mathrm{H}^{+}$transport. In effect, as we reported in the paper, the modification of the Nafion membrane with the carbon did allow the better ionic conduction of the proton. As shown in Table 1, the current-voltage (I-V) characteristic of the modified membrane, shows a limiting current density $\left(20.02 \mathrm{~mA} / \mathrm{cm}^{2}\right)$ less than the pristine membrane (without modification, i.e. $32.59 \mathrm{~mA} / \mathrm{cm}^{2}$ ), which is quite reasonable. In effect, with the modified membrane, the coefficient diffusion of the proton in the diffusion layer immediately adjacent to the membrane is less than that of the pristine, which leads to a rapid depletion of the proton from the diffusion layer, and thus a quick transfer through the membrane. Compared to metal cations present in the anode compartment, the proton moves more rapidly, in agreement with previous data reported in the literature. The presence of carbonaceous support (carbon powder) in the membrane suggests that it may be capable of conducting electrons. For this, we characterized the Nafion117 membrane using cyclic volt-amperometry with three electrodes.

\section{Cyclic voltammetry of Nafion membrane and carbon felt}

Cyclic voltammetry (CV) is now used almost routinely to characterize bio-anodes and advance in understanding electron transport and transfer mechanisms. The main objective of a catalytic $\mathrm{CV}$ is to characterize the bio-electrode properties in particular oxidation and reduction, by exploiting the substrate. Catalytic CVs are generally performed in stationary mode only, i.e. with a potential scan rate low enough for reactions and electron transport/transfer steps to balance each other. Experimentally, a low scan rate is most often used to ensure such a condition. The stationary catalytic CVs give the current that the electrode could provide under the applied potential over the whole range of scanned potentials, and thus provides a complete characterization of the electroactive biofilm electrocatalytic behavior [26].

The modification of the Nafion membrane with the carbon powder has been made in evidence by $\mathrm{CV}$. Fig. 8 shows that the redox signal of $\mathrm{K}_{3} \mathrm{Fe}(\mathrm{CN})_{6}$ is visible on the carbon modified Nafion 117 membrane with the appearance of the two oxidation and reduction peaks in cycle IV. This demonstrates that modified-Nafion 117 is a good electronic conductor. Whilst, Fig. 9 illustrates the oxidation of the substrate by the biofilm on the carbon felt [31].

\section{Electrochemical impedance spectroscopy (EIS) of membranes and carbon felt}

EIS is a powerful method to understand and study electron-transfer mechanisms and different properties of pure and heterogeneous biofilms. Many works studied the various parameters that influence impedance in Microbial Fuel Cells (MFCs) on biofilm electrodes. The first studies were only focused on determining the internal resistance of MFCs with a basic interpretation of impedance spectra. Other parameters investigated were the electrode material [28]. Recently, the electrochemical impedance experiments were also used 


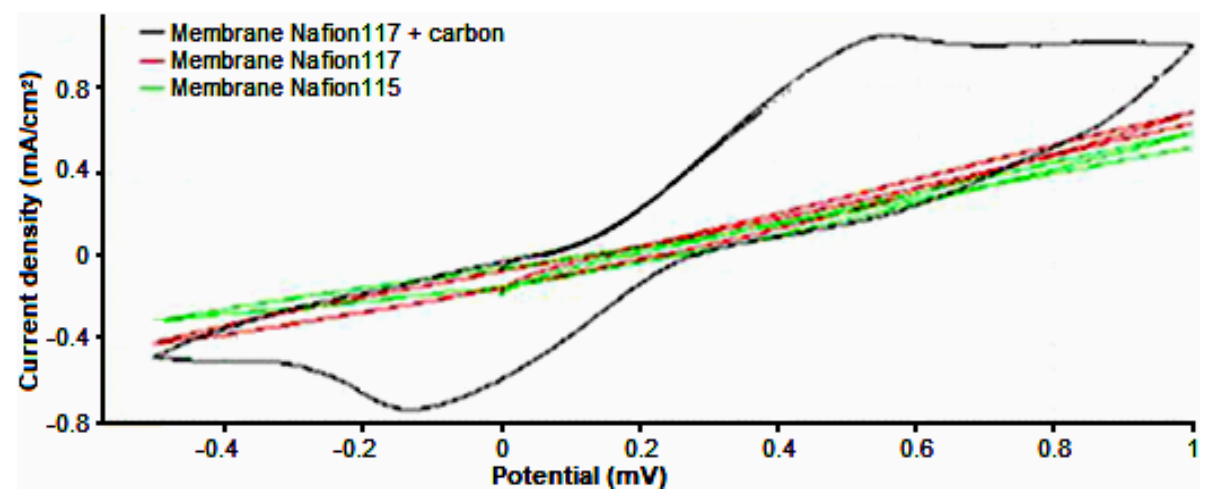

Fig 8. Cyclic voltammetry of the Nafion 117 membrane modified with carbon

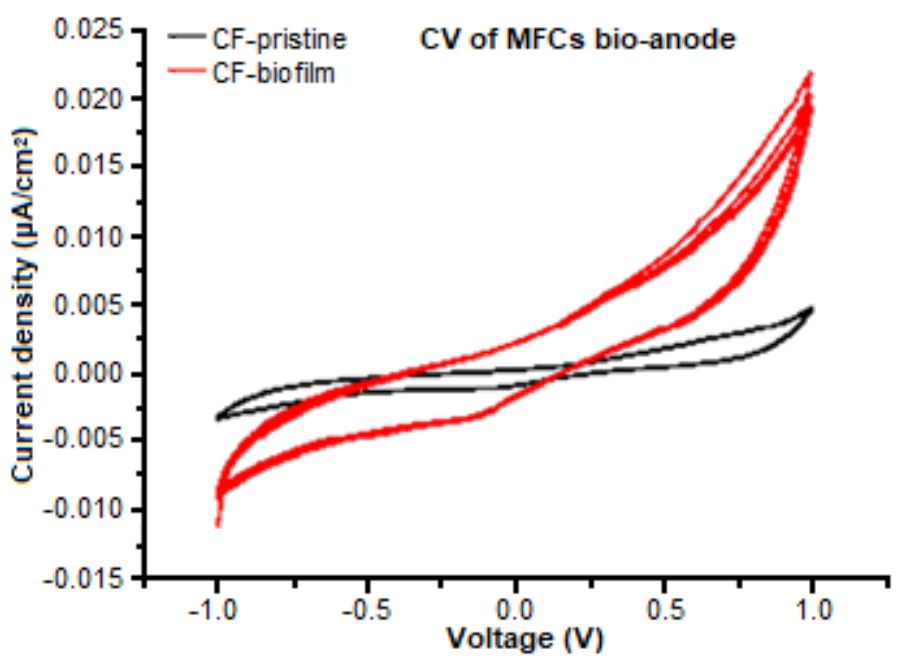

Fig 9. CV of carbon felt

to understand the phenomena related to bioelectrochemistry, such as the ionic strength of the medium [29] effects of the $\mathrm{pH}$, and the presence of microbially secreted mediators [30].

EIS using a Nyquist plot is one of some methods used for evaluating the internal resistance of an MFC. This method is preferred compared to the others as the dynamic response of the system is measured, even though it requires the use of a potentiostat with EIS software. EIS is based on superimposing the applied potential of a working electrode to result in a sinusoidal signal with a small amplitude. By varying the frequency of the sinusoidal signal and plotting the measured electrode impedance, detailed information can be obtained on the system [31].

To confirm the electron conduction of the carbon modified Nafion117 membrane, we performed a characterization by three-electrode impedance spectroscopy. The EIS Nyquist diagrams have been removed to extract the values of the electric resistance of electrolyte by extrapolation of the Nyquist diagram to infinite frequency [32]. The values are summarized in Table 2. As can be seen, the membrane modified with three thin films of CP displays the smallest electric resistance i.e. the highest electric conductivity. Besides, Fig.10 and 11 show the Nyquist diagrams and SEM image of carbon felt with and without biofilm.

Table 2. Surface electrolyte resistances of the three modified membranes (MM) with carbon powder (CP) extracted from Nyquist diagrams

\begin{tabular}{lc}
\hline MM with CP & $\operatorname{Re}\left(\mathrm{Ohm} \mathrm{cm}^{-2}\right)$ \\
\hline One thin film & 0.85 \\
Two thin films & 0.77 \\
Three thin films & 0.26 \\
\hline
\end{tabular}

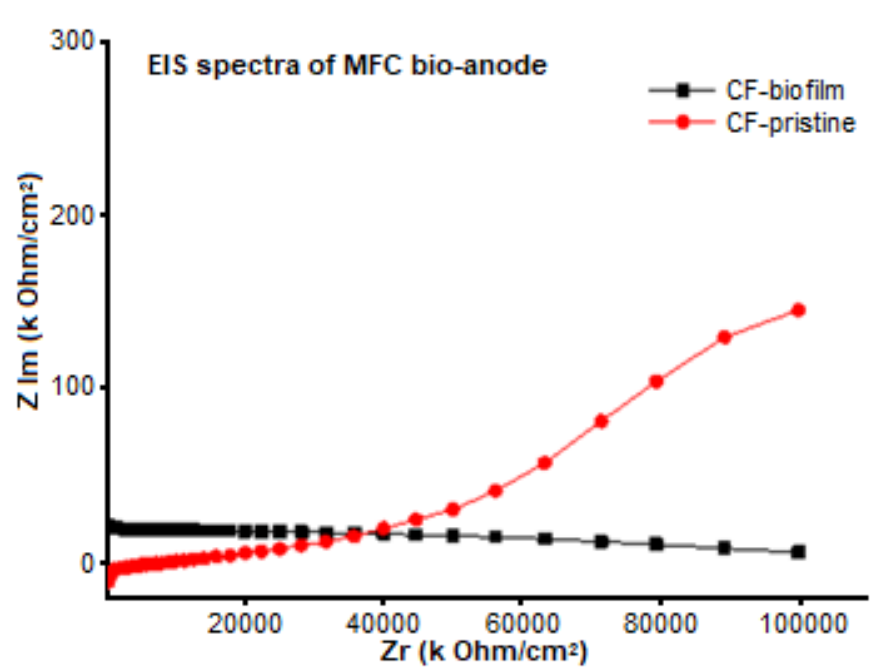

Fig 10. EIS of carbon felt 

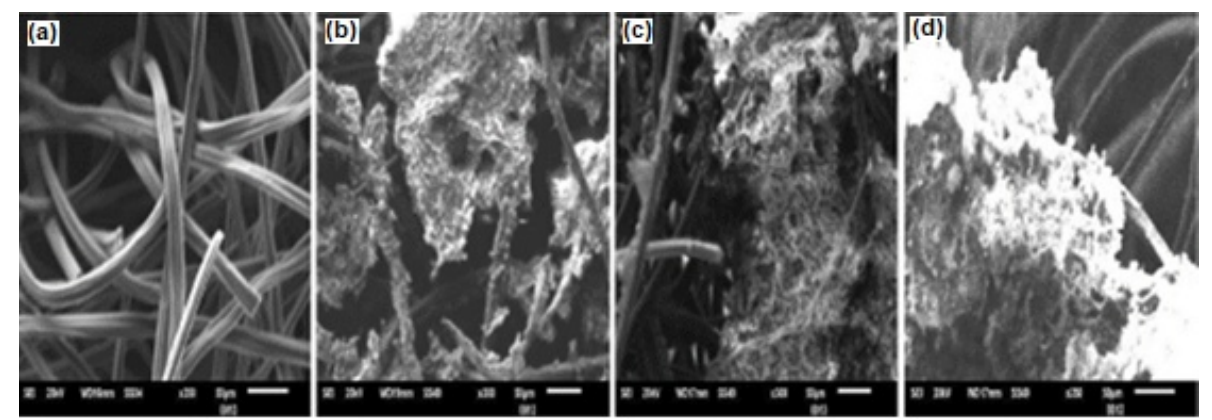

Fig 11. SEM images (magnification $50 \mathrm{~lm}$ ) confirm reformation of biofilms resulting from sonication of successive generations: (a) pristine CF; (b) biofilm of $1^{\text {st }} \mathrm{G}$; (c) biofilm of $2^{\text {nd }} \mathrm{G}$; (d) biofilm of $3^{\text {rd }} \mathrm{G}$

The values of the electric resistance confirm that the increase in the amount of carbon deposited on the polymer matrix of Nafion117 causes the decrease of resistance of this membrane (used as bio-anode). However, it becomes electrically more conductive [3335]. The carbon dioxide modified Nafion117 membrane can be used as a bio-anode in the MFC. This latter becomes capable to allow the connection of biofilm on its surface. Since the modified membrane becomes a highly electronic conductor, it can satisfactorily be used as a bioanode in the conception of a novel MFC device for the production of small bio-energy and depollution of the environment [33-35].

\section{Power Generation of MFCs}

The constituents of different MFCs is presented in Table 3 and illustrated schematically in Fig. 12. The performance of the MFC1 was monitored during prolonged operation using bio-anode carbon felt, cathode stainless steel plate, and separator (membrane Nafion117)
[36-37]. The cell was operated over an external load resistance of $1000 \Omega$. The current Density across the external resistance reached a maximum of more than $290 \mathrm{~mA} / \mathrm{m}^{2}$ approximately $120 \mathrm{~h}$ after the beginning of the experiment and falling to about $60 \%$ of its first maximum value after a further $50 \mathrm{~h}$ (Fig. 13) [38-40]. The addition of extra nutrients $(5 \mathrm{~mL}$ of sodium acetate added as indicated by the first squared blue symbol) restored the current density to the second maximum value $\left(250 \mathrm{~mA} / \mathrm{m}^{2}\right)$, showing that the decline in current had been due to exhaustion of nutrients in the medium. After the potential had subsequently fallen again, another addition of the same amount of sodium acetate increased the current density. However, after $700 \mathrm{~h}$ the current density decreases despite the addition of fuel. At last, it reached the minimum value $\left(30 \mathrm{~mA} / \mathrm{m}^{2}\right)$, after $1200 \mathrm{~h}$.

The MFC2 followed the same behavior as the MFC1, but with a large difference between their current densities (50\%) in the beginning. This difference decreased with time. However, the current densities of

Table 3. Constituents of different MFCs

\begin{tabular}{llll}
\hline Type of MCF & Bio-anode & Cathode & Separator \\
\hline MCF1 & - Carbon felt & - Stainless Steel 316 & Nafion117 \\
& $-6.5 \mathrm{~cm}^{2}$ & $-8 \mathrm{~cm}^{2}$ & \\
MCF2 & - Carbon felt & - Stainless Steel 316 & Nafion117 modified with \\
& $-6.5 \mathrm{~cm}^{2}$ & $-8 \mathrm{~cm}^{2}$ & carbon powder KS6 \\
MCF3 & - Nafion117 modified with & - Stainless Steel 316 & Nafion117 \\
& carbon powder KS6 & $-8 \mathrm{~cm}^{2}$ & \\
MCF4 & $-6.5 \mathrm{~cm}^{2}$ & & \multirow{2}{*}{ Nafion117 modified with } \\
& - Nafion117 modified with & - Stainless Steel 316 & carbon powder KS6 \\
& carbon powder KS6 & $-8 \mathrm{~cm}^{2}$ & \\
\hline
\end{tabular}

Mustapha Abdeldjabar Charef et al. 


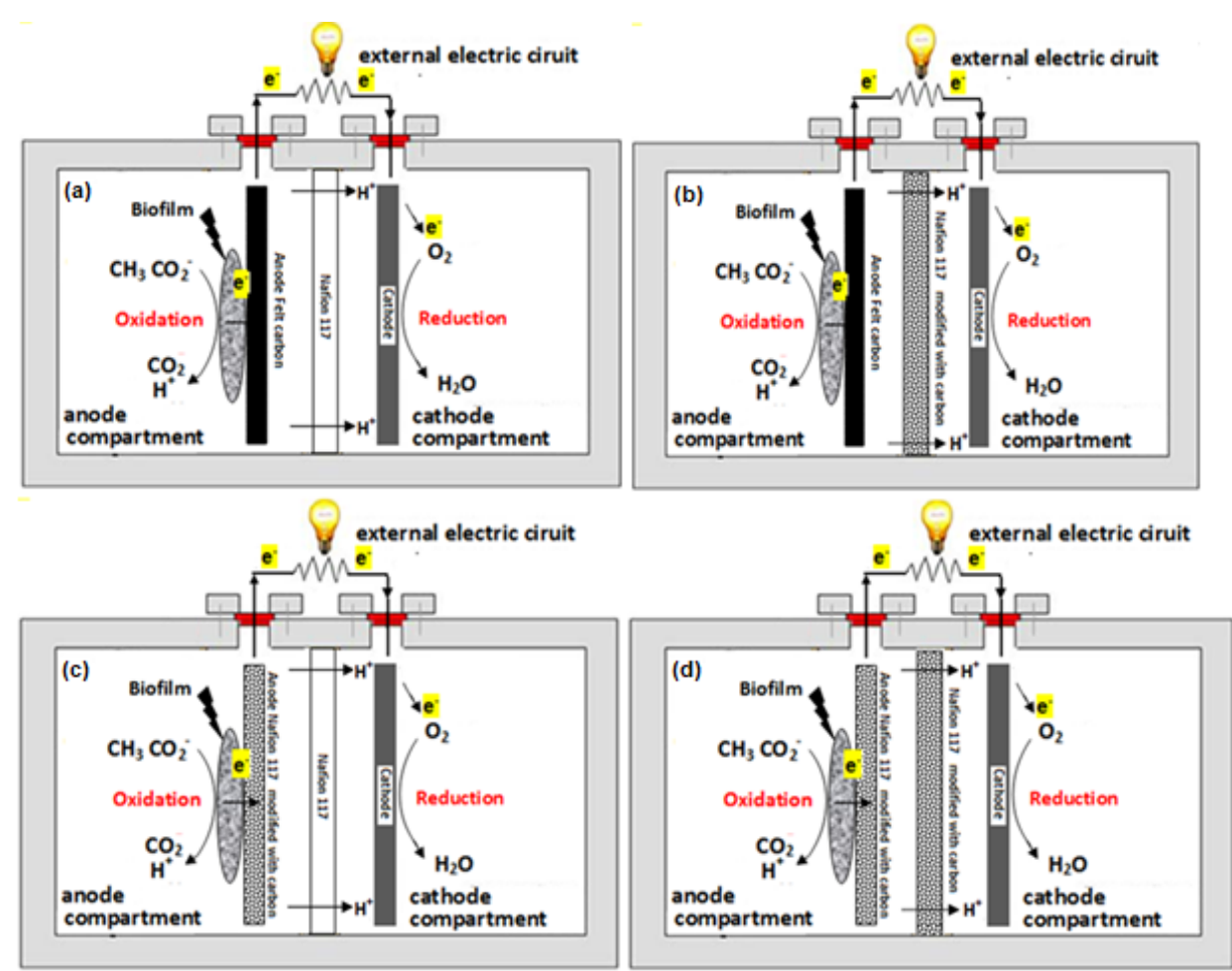

Fig 12. Schemes of MFCs according to Table 3 (a-d); (a) MFC1, (b) MFC2, (c) MFC3, (d) MFC4

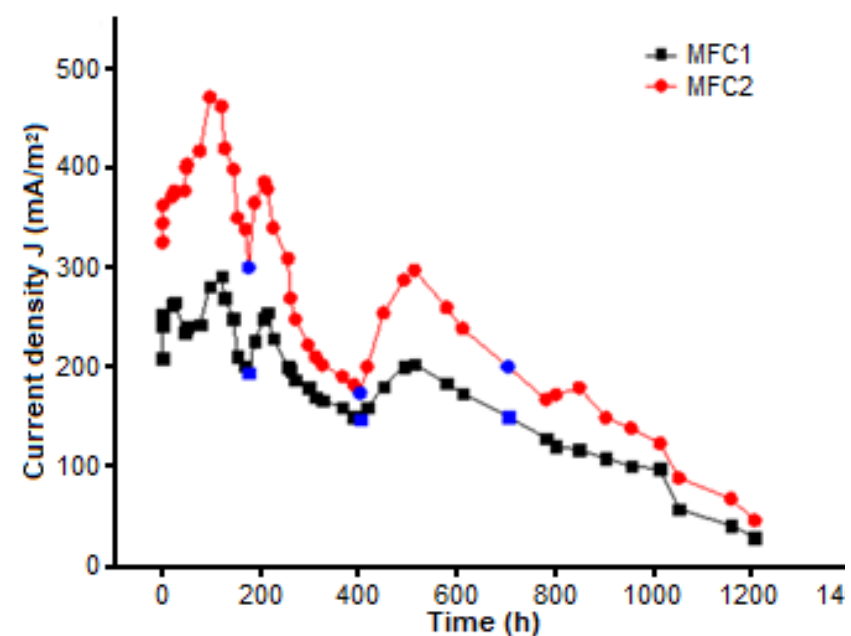

Fig 13. (-) Evolution of current density of MFC1 (membrane separator Nafion117 unmodified), (-) Evolution of current density of MFC2 (membrane separator Nafion117 modified with carbon powder), (-) Indicate additions of $5 \mathrm{~mL}$ of sodium acetate; with an external resistance of $(1000 \Omega)$

both MFCs tended towards the same minimum value $\left(50 \mathrm{~mA} / \mathrm{m}^{2}\right)$ after $1200 \mathrm{~h}$. It may be concluded that the modification of the membrane with carbon powder enhances its proton conduction.
The performance of the MFClwas studied for a long time. It reaches the maximum value $\left(290 \mathrm{~mA} / \mathrm{m}^{2}\right)$ after $120 \mathrm{~h}$. About $60 \%$ of this density is lost after $50 \mathrm{~h}$ (Fig. 13). The performance of MFC1 increases to $250 \mathrm{~mA} / \mathrm{m}^{2}$ after the addition of $5 \mathrm{~mL}$ sodium acetate. The value of J decreases $30 \mathrm{~mA} / \mathrm{m}^{2}$ after $1200 \mathrm{~h}$ even with the addition of a carburant. The MFC2 follows the same pace as the MFC1 but with a higher current density of about $50 \%$, so the MFC2 modified with carbon gives more energy.

This increase may be due to the change in the material caused by the modification of the membrane with carbon. On the other hand, the two current densities approach each other as the time is running out. This phenomenon can be explained by the fact that the carbon powder is detached from the modified membrane. This phenomenon can be explained by the fact that the carbon powder is detached from the modified membrane. Despite this, carbon-modified MFC2 remains the most energy-efficient biopile. To confirm this conclusion, it was necessary to use electrochemical characterization techniques such as volt-amperometry, cyclic voltammetry, and electrochemical impedance spectroscopy. 

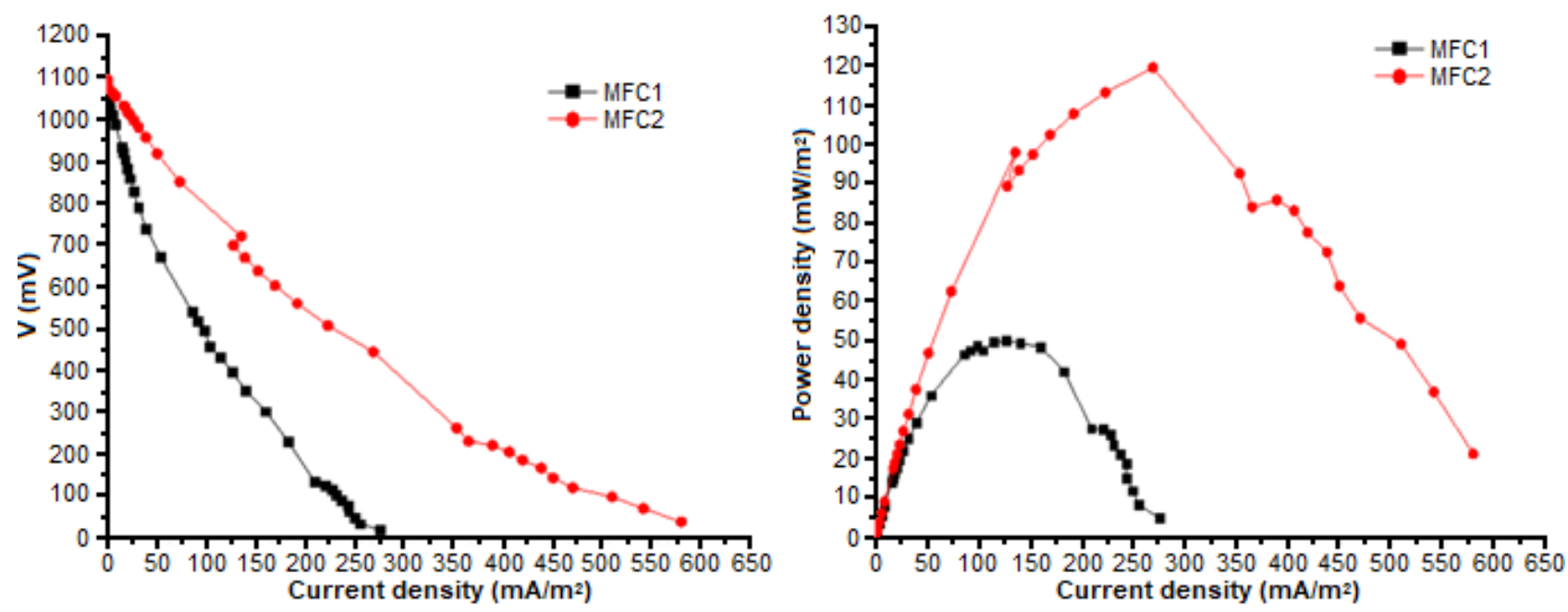

Fig 14. Polarization curves of MFC1 and MFC2

\section{Polarization and Power Curves}

Fig. 14 shows the polarization and power curves of the studied MFC. It can be obtained from the polarizationcurve that the internal resistance of the MFC was $1000 \Omega$.From the power curves, it was observed that the MFC1 generated a maximum power density of 50 $\mathrm{mW} / \mathrm{m}^{2}$, which corresponded to a density current of 126 $\mathrm{mA} / \mathrm{m}^{2}$ at the cell voltage $400 \mathrm{mV}$. The MFC2 followed the same behavior as the MFC1, but with a large difference between their power densities of $120 \mathrm{~mW} / \mathrm{m}^{2}$ which corresponds toa current density of $270 \mathrm{~mA} / \mathrm{m}^{2}$ at the cell voltage $450 \mathrm{mV}$. It may be concluded that the modification of the membrane with carbon powder enhances its performance.

\section{Modified Nafion Membrane as Bio-Anode in MFC}

As the membrane demonstrated high electronic conductivity, we considered the MFC device with this membrane. The difference between these two MFCs is the separator between the two compartments. In MFC3, the bio-anode is the Nafion117 membrane modified with carbon powder, the separator is the virgin Nafion 117 membrane and the cathode used is stainless steel 316. In MFC4, the bio-anode used is Nafion117 membrane modified with the carbon powder, the separator is the modified Nafion117 membrane with carbon and the cathode used is stainless steel 316 .

\section{Stability of MFC3 and MFC4}

In the case where the modified membrane was used both as separator and bio-anode, we obtained similar behavior and approximately the same current density as MFC1 and MFC2. The advantage of using the MFC4 was to avoid the corrosion of the bio-anode. It may

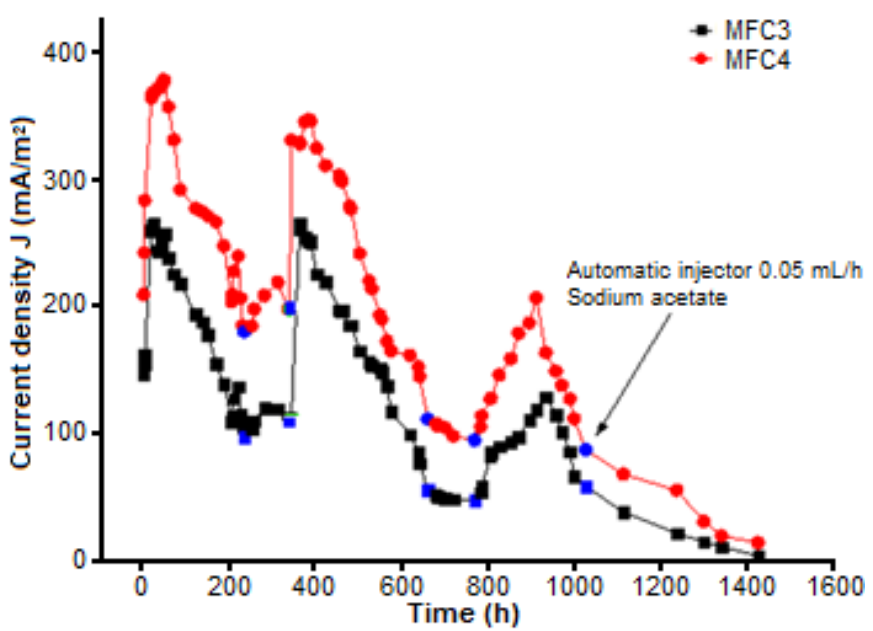

Fig 15. (-) Evolution of current density of MFC3 (anode Nafion117 modified with carbon powder membrane separator Nafion117 unmodified), (•) Evolution of current density of MFC4 (anode Nafion 117 modified with carbon powder membrane separator Nafion117 membrane separator Nafion 117 modified with carbon powder), ( $\bullet$ ) indicate additions of $5 \mathrm{~mL}$ of sodium acetate with an external resistance of $(1000 \Omega)$ 

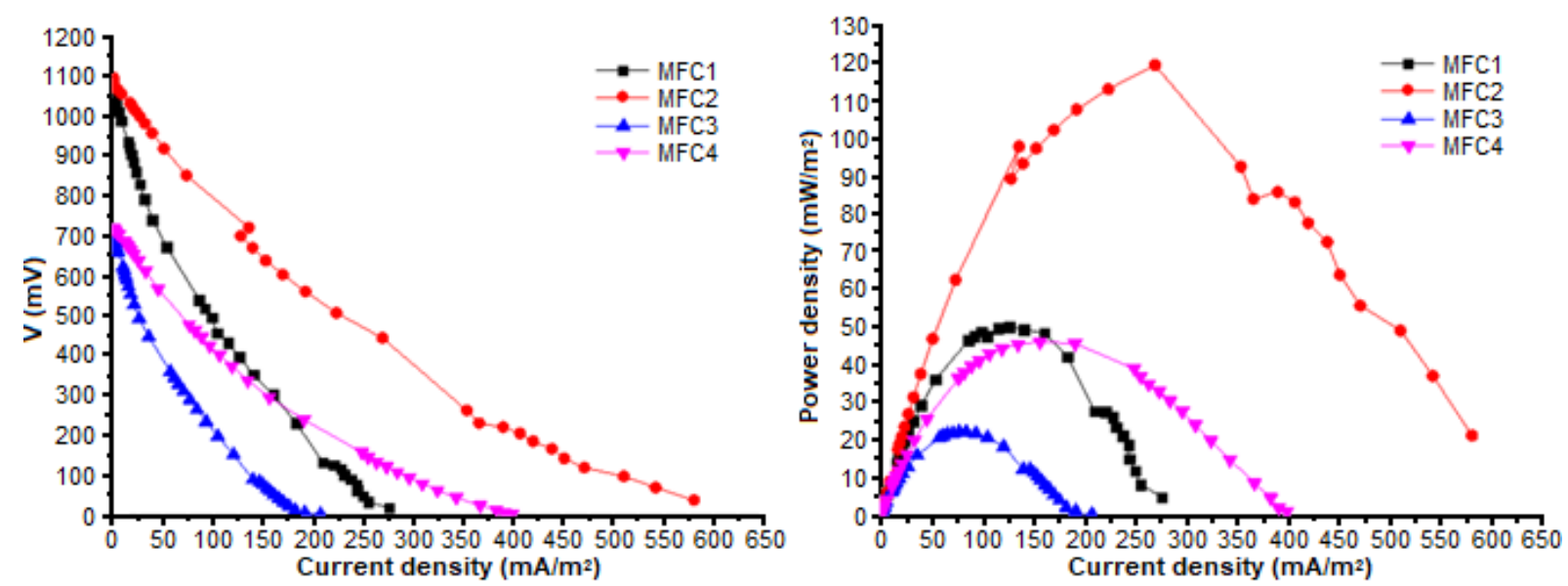

Fig 16. Polarization curves of 4 MFCs

Table 4. Comparison between performances of MFCs

\begin{tabular}{lccc}
\hline Type of MFC & $\begin{array}{c}\text { Initial Current Density } \\
\left(\mathrm{mA} / \mathrm{m}^{2}\right)\end{array}$ & $\begin{array}{c}\text { Maximum Current Density } \\
\left(\mathrm{mA} / \mathrm{m}^{2}\right)\end{array}$ & $\begin{array}{c}\text { Power Density } \\
\left(\mathrm{mW} / \mathrm{m}^{2}\right)\end{array}$ \\
\hline MFC1 & 210 & 292 & 50 \\
MFC2 & 327 & 470 & 119 \\
MFC3 & 145 & 265 & 22 \\
MFC4 & 209 & 379 & 45 \\
\hline
\end{tabular}

be concluded that the modification of the membrane with carbon powder used either as bio-anode and separator, enhances its proton conduction and electron production.

Fig. 16 shows the characterizations of the MFC3 and MFC4. A current increase has been observed, indicating the formation of a biofilm and its connection to the anode. This confirms both the good conduction of the Nafion 117 membrane modified with graphite carbon, as electrode, but also its ability to connect the microbial biofilm. Moreover, it was noticed that the MFC with a modified membrane either as separator or bio-anode, was stable and kept its form. Its role was to improve the electronic conduction as far as the modified Nafion membrane with carbon powder is known as proton/electron conductor.

Besides, as shown in Table 4 and Fig. 16, the comparison between the four MFCs reveals that the effect of the modification of the membrane on the performances of the microbial fuel cell indicating the possibility of using this membrane as an electrode, even if in the latter two MFC3 and MFC4. The power results are lower and the capacity of the membrane is made conductive. It establishes an electrical connection between the bacterial medium and the bio-anode. This point is certainly the explanation of the increase in the performance of the biopiles in the presence of membrane modified with the carbon powder (MFC1 and MFC2). The membrane acts as an electrode and behaves like an anode at the same time. This property is at the cause of the performances observed. We have shown by the voltammetric technique that the membrane permeability was not modified to explain the increase in observed power.

\section{- CONCLUSION}

The characterization of the Nafion117 membrane used in a microbial fuel cell was carried out under the operating conditions. The results showed moderate differences in membrane permeability which lead to the conclusion that this material could be used as a microbial fuel cell separator. Moreover, the modification of the Nafion 117 membrane with carbon powder made it possible to obtain a mixed conductive membrane material (ionic and electronic) which we were able to characterize. The integration of this modified membrane in a microbial fuel cell has shown its ability 
to increase device power. According to our first analyzes, it seems that the properties of electronic conductivity associated with the capacity of connection of a biofilm by the membrane explain this performance. The preliminary results should be supplemented by analyzes of the presence of biofilm on the membrane. In the absence of biofilm, this would demonstrate a moderate transfer of electrons from the bacterial to the electrode via redox mediators secreted by microbial cells.

\section{- REFERENCES}

[1] Cheng, S., Xing, D., Call, D.F., and Logan, B.E., 2009, Direct biological conversion of electrical current into methane by electro methanogenesis, Environ. Sci. Technol., 43, 3953-3958.

[2] Logan, B.E., 2009, Exoelectrogenic bacteria that power microbial fuel cells, Nat. Rev. Microbiol., 7 (5), 375-381.

[3] Kato, S., 2016, Microbial extracellular electron transfer and its relevance to iron corrosion, Microb. Biotechnol., 9 (2), 141-148.

[4] Djellali, M., Kameche, M., Kebaili, H., Bohent, M.M., and Benhamou, A., 2019, Synthesis of nickel-based layered double hydroxide (LDH) and their adsorption on carbon felt fibers: Application as lowcost cathode catalyst in microbial fuel cell (MFC), Environ. Technol., 0 (0), 1-13.

[5] Kebaili, H., Kameche, M., Innocent, C., Benayyad, A., Kosimaningrum, W.E., and Sahraoui, T., 2019, Scratching and transplanting of electro-active biofilm in fruit peeling leachate by ultrasound: Reinoculation in new microbial fuel cell for enhancement of bio-energy production and organic matter detection, Biotechnol. Lett., 42 (6), 965-978.

[6] Zhang, X., Cheng, S., Liang, P., Huang, X., and Logan, B.E., 2011, Scalable air cathode microbial fuel cells using glass fiber separators, plastic mesh supporters, and graphite fiber brush anodes, Bioresour. Technol., 102 (1), 372-375.

[7] Cheng, S., Liu, H., and Logan, B.E., 2006, Increased performance of single-chamber microbial fuel cells using an improved cathode structure, Electrochem. Commun., 8 (3), 489-494.
[8] Ouis, M., Kameche, M., Innocent, C., Charef, M., and Kebaili, H., 2018, Electro-polymerization of pyrrole on graphite electrode: Enhancement of electron transfer in bioanode of microbial fuel cell, Polym. Bull., 75 (2), 669-684.

[9] Niessen, J., Schröder, U., Harnisch, F., and Scholz, F., 2005, Gaining electricity from in situ oxidation of hydrogen produced by fermentative cellulose degradation, Lett. Appl. Microbiol., 41 (3), 286-290.

[10] Gil, G.C., Chang, I.S., Kim, B.H., Kim, M., Jang, J.K., Park, H.S., and Kim, H.J., 2003, Operational parameters affecting the performance of a mediator-less microbial fuel cell, Biosens. Bioelectron., 18 (4), 327-334.

[11] Heilmann, J., and Logan, B.E., 2006, Production of electricity from proteins using a microbial fuel cell, Water Environ. Res., 78 (5), 531-537.

[12] Zhang, B.G., Zhou, S.G., Zhao, H.Z., Shi, C.H., Kong, L.C., Sun, J.J., Yang, Y., and Ni, J.R., 2010, Factors affecting the performance of microbial fuel cells for sulfide and vanadium (V) treatment, Bioprocess. Biosyst. Eng., 33 (2), 187-194.

[13] Kondaveeti, S., Choi, K.S., Kakarla, R., and Min, B., 2014, Microalgae Scenedesmus obliquus as renewable biomass feedstock for electricity generation in microbial fuel cells (MFCs), Front. Environ. Sci. Eng., 8 (5), 784-791.

[14] Cercado-Quezada, B., Delia, M.L., and Bergel, A., 2010, Treatment of dairy wastes with a microbial anode formed from garden compost, J. Appl. Electrochem., 40 (2), 225-232.

[15] Chaudhuri, S.K., and Lovley, D.R., 2003, Electricity generation by direct oxidation of glucose in mediatorless microbial fuel cells, Nat. Biotechnol., 21 (10), 1229-1232.

[16] Cheng, S., Liu, H., and Logan, B.E., 2006, Increased performance of single-chamber microbial fuel cells using an improved cathode structure, Electrochem. Commun., 8 (3), 489-494.

[17] Zhu, X., and Ni, J., 2009, Simultaneous processes of electricity generation and $p$-nitrophenol degradation in a microbial fuel cell, Electrochem. Commun., 11 (20, 274-277. 
[18] Read, S.T., Dutta, P., Bond, P.L., Keller, J., and Rabaey, K., 2010, Initial development and structure of biofilms on microbial fuel cell anodes, $B M C$ Microbiol., 10 (1), 98.

[19] Zerrouki, A., Kameche, M., Kebaili, H., Boukoussa, I.S., Flitti, M.A., Ilikti, H., and Innocent, C., 2018, An investigation on polymer ion exchange membranes used as separators in low energy microbial fuel cells, Polym. Bull., 75 (11), 4947-4965.

[20] Hamani, H., Bouamrane, R., Kameche, M., Innocent, C, and Derriche, Z., 2013, Transport number and current voltage of a cation exchange membrane equilibrated in aqueous and organic solutions, Phys. Chem. Liq., 51 (3), 265-280.

[21] Choi, J.H., Lee, H.J., and Moon, S.H., 2001, Effects of electrolytes on the transport phenomena in a cationexchange membrane, J. Colloid Interface Sci., 238 (1), 188-195.

[22] Lachachi, Z., Kameche, M., Bendjeda, S., Meddah, K., Hamani, H., Boumediene, H., and Innocent, C., 2016, Study of proton leakage at interface of anion exchange membrane in solutions of acids, salts and solvents using current-voltage characteristics, Chem. Eng. Commun., 203 (4), 566-574.

[23] Choi, Y.J., Park, J.M., Yeon, K.H., and Moon, S.H., 2005, Determination of the limiting current density in electrodialysis desalination as an empirical function of linear velocity, Desalination, 190 (1-3), 43-50.

[24] Choi, Y.J., Park, J.M., Yeon, K.H., and Moon, S.H., 2002, Direct measurement of concentration distribution within the boundary layer of an ionexchange membrane, J. Colloid Interface Sci., 251 (2), 311-317.

[25] Grosse, W., Champavert, J., Gambhir, S., Wallace, G.G., and Moulton, S.E., 2013, Aqueous dispersions of reduced graphene oxide and multi wall carbon nanotubes for enhanced glucose oxidase bioelectrode performance, Carbon, 61, 467-475.

[26] Rousseau, R., Délia, M.L., and Bergel, A., 2014, A theoretical model of transient cyclic voltammetry for electroactive biofilms, Energy Environ. Sci., 7 (3), 10791094.
[27] Varanasi, J.L., Nayak, A.K., Sohn, Y., Pradhan, D., and Das, D., 2016, Improvement of power generation of microbial fuel cell by integrating tungsten oxide electrocatalyst with pure or mixed culture biocatalysts, Electrochim. Acta, 199, 154-163.

[28] Ouitrakul, S., Sriyudthsak, M., Charojrochkul, S., and Kakizono, T., 2007, Impedance analysis of biofuel cell electrodes, Biosens. Bioelectron., 23 (5), 721-727.

[29] Aaron, D., Tsouris, C., Hamilton, C.Y., and Borole, A.P., 2010, Assessment of the effects of flow rate and ionic strength on the performance of an aircathode microbial fuel cell using electrochemical impedance spectroscopy, Energies, 3 (4), 592-606.

[30] Ramasamy, R.P., Gadhamshetty, V., Nadeau, L.J., and Johnson, G.R. 2009, Impedance spectroscopy as a tool for non-intrusive detection of extracellular mediators in microbial fuel cells, Biotechnol. Bioeng., 104 (5), 882-891.

[31] Logan, B.E., Hamelers, B., Rozendal, R., Schröder, U., Keller, J., Freguiac, S., Aelterman, P., Verstraete, W., and Rabaey, K., 2006, Microbial fuel cells: Methodology and technology, Environ. Sci. Technol., 40 (17), 5181-5192.

[32] Zhang, S., You, J., Kennes, C., Chang, Z., Ye, J., Chen, D., Chen, J., and Wang, L., 2018, Current advances of VOCs degradation by bioelectrochemical systems: A review, Chem. Eng. J., 334, 2625-2637.

[33] Sanjuan, B., Millot, R., Innocent, C., Dezayes, C., Scheiber, J., and Brach, M., 2016, Major geochemical characteristics of geothermal brines from the Upper Rhine Graben granitic basement with constraints on temperature and circulation, Chem. Geol., 428, 27-47.

[34] Xu, F., Kameche, M., and Innocent, C., 2013, Transport of ions and solvent through a Nafion membrane modified with polypyrrole, J. Membr. Sep. Technol., 1 (2), 108-116.

[35] Kebaili, H., Kameche, M., Innocent, C., Ziane, F.Z., Sabeur, S.A., Sahraoui, T., Ouis, M., Zerrouki, A., and Charef, M.A., 2021, Treatment of fruit waste leachate using microbial fuel cell: Preservation of 
agricultural environment, Acta Ecol. Sin., 41 (2), 97105.

[36] Djellali, M., Kameche, M., Kebaili, H., Benhamou, A., Bouhent, M., and Innocent, C., 2020, "Utilization of double-layered hydroxides for enhancement of dissolved oxygen reduction in microbial fuel cell: An approach for the evaluation of coulomb efficiency" in ICREEC 2019, Eds. Belasri, A., and Beldjilali, S., Springer Proceedings in Energy, Springer, Singapore, 239-244.

[37] Zerrouki, A., Kameche, M., Kebaili, H., Amer, A.A., and Innocent, C., 2020, "Electro-catalytic electrodes and ionic exchange membranes in microbial fuel cell" in ICREEC 2019, Eds. Belasri, A., and Beldjilali, S., Springer Proceedings in Energy, Springer, Singapore, 211-217.

[38] Kebaili, H., Kameche, M., Innocent, C., Kosimaningrum, W.E., and Sahraoui, T., 2020,
"Growth of electroactive biofilm onto carbon felt bioanode in microbial fuel cell: Enhancement of bioenergy production" in ICREEC 2019, Eds. Belasri, A., and Beldjilali, S., Springer Proceedings in Energy, Springer, Singapore, 205-210.

[39] Benayyad, A., Kameche, M., Kebaili, H., and Innocent, C., 2021, "Design of a microbial fuel cell used as a biosensor of pollution emitted by oxidized organic matter" in Advances in Renewable Hydrogen and Other Sustainable Energy Carriers, Eds. Khelaff, A., Springer Proceedings in Energy, Springer, Singapore, 279-284.

[40] Ci, J., Cao, C., Kuga, S., Shen, J., Wu, M., and Huang, Y., 2017, Improved performance of microbial fuel cell using esterified Corncob cellulose nanofibers to fabricate air-cathode gas diffusion layer, ACS Sustainable Chem. Eng., 5 (11), 9614-9618. 